\title{
Impact of the Connected Medicine collaborative in improving access to specialist care: a cross-sectional analysis
}

\author{
Clare Liddy MD MSc, Emma Boulay MA, Lois Crowe BA, Maxine Dumas-Pilon MD, Neil Drimer MHSc, \\ Gerard Farrell MD, Laurie Ireland MD, Christine (Kirby) Kirvan MA, Veronique Nabelsi PhD, \\ Alexander Singer MB BAO BCh, Margot Wilson MSN, Erin Keely MD
}

\section{Abstract}

Background: In 2017, the Canadian Foundation for Healthcare Improvement launched the Connected Medicine collaborative to support the implementation, spread and adaptation of 2 innovative remote consult solutions - the Champlain Building Access to Specialists through eConsultation (BASE) eConsult service and the Rapid Access to Consultative Expertise (RACE) service - across Canada. We evaluated the impact of the programs implemented through the collaborative.

Methods: We conducted a cross-sectional analysis of data from provincial teams that participated in the Connected Medicine collaborative, which took place between June 2017 and December 2018 in 7 provinces across Canada (British Columbia, Alberta, Saskatchewan, Manitoba, Quebec, New Brunswick, Newfoundland and Labrador). Data included utilization data collected automatically by the BASE and RACE services and, where available, responses to surveys completed by primary care providers at the end of each case. We assessed programs on the following outcomes: usage (i.e., number of cases completed, average specialist response time), number of specialties available, impact on primary care provider's decision to refer and impact on emergency department visits. We performed descriptive analyses.

Results: Ten provincial teams participated in the collaborative and implemented or adapted either the RACE service (4 teams), the BASE service (5 teams) or a combination of the 2 services (1 team). Average monthly case volume per team ranged from 14.7 to 424.5. All programs offered multispecialty access, with specialists from 5 to 37 specialty groups available. Specialists responded to eConsults within 7 days in $80 \%(n=294 / 368)$ to $93 \%(n=164 / 176)$ of cases. Six programs provided survey data on avoidance of referrals, which occurred in $48 \%(n=667 / 1389)$ to $76 \%(n=302 / 398)$ of cases. Two programs reported on the avoidance of potential emergency department visits, noting that originally considered referrals were avoided in $28 \%(n=138 / 492)$ and $74 \%(n=127 / 171)$ of cases, respectively.

Interpretation: The 2 innovative virtual care solutions implemented through the Connected Medicine collaborative received widespread usage and affected primary care providers' decisions to refer patients to specialists. The impact of these models of care in multiple settings shows that they are an effective means to move beyond the pilot stage and achieve spread and scale.

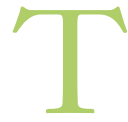

he Canadian health care system struggles with excessive wait times for specialist care. ${ }^{1,2}$ A 2016 study found that $56 \%$ of Canadians reported wait times of more than 4 weeks for a specialist appointment versus an international average of $36 \%$, placing Canada last among the 11 countries surveyed. ${ }^{1}$ Studies based solely in Canada paint a similar picture, reporting median wait times for specialist care of 5 to 11 weeks. ${ }^{3-6}$ In addition to the frustration and anxiety produced by waiting for care, excessive wait times can have a negative effect on patients' health outcomes. ${ }^{2}$

Innovators across Canada are developing novel solutions to address the issue of excessive wait times for specialist care. However, Canada's fragmented health care system and immense geographic size impose substantial barriers to scaleup of known solutions. ${ }^{7,8}$ Many promising projects languish at the pilot phase and are unable to expand beyond the regions where they were originally implemented, ${ }^{8,9}$ an issue that led Canada to be dubbed "a country of perpetual pilot projects."

In an effort to address this problem, the Canadian Foundation for Healthcare Improvement partnered with the College of Family Physicians of Canada, Canada Health Infoway and the Royal College of Physicians and Surgeons of Canada to launch the Connected Medicine quality improvement

\section{Competing interests: None declared.}

This article has been peer reviewed.

Correspondence to: Clare Liddy, cliddy@uottawa.ca

CMAJ Open 2021 December 14. DOI:10.9778/cmajo.20200210 
collaborative, a program that supports the implementation, spread and adaptation of proven remote access innovations. ${ }^{10}$

The purpose of our study was to evaluate the impact of 2 services, the Champlain BASE (Building Access to Specialists through eConsultation) eConsult service and the Rapid Access to Consultative Expertise (RACE) service, implemented through the Connected Medicine collaborative. This assessment of the collaborative's effectiveness will inform future endeavours for spreading and scaling up health care innovations.

\section{Methods}

\section{Design and setting}

We performed a cross-sectional analysis of data from provincial teams that participated in the Connected Medicine collaborative, which took place across Canada between June 2017 and December 2018. Although Canadian Forces Health Services implemented a national program using the RACE model, utilization data were not available and thus were not included in this study.

The Connected Medicine quality improvement collaborative was an 18-month program that connected health care improvement teams interested in improving access to specialist care in their regions with proven remote-access innovations. ${ }^{10}$ Participating teams received support from the Canadian Foundation for Healthcare Improvement in the form of seed funding to support the implementation, spread, scale and evaluation of their innovation. (Since this study was conducted, the Canadian Foundation for Healthcare Improvement has amalgamated with the Canadian Patient Safety Institute to become Healthcare Excellence Canada.) The collaborative also provided curricular tools to enhance the teams' quality improvement skills, including educational webinars, access to a network of expert coaches and faculty, in-person workshops and peer-to-peer networking. In particular, the collaborative, through its various features, allowed sites to learn and to work through implementation challenges together, by providing regular opportunities to share, gain advice and problem-solve with the 2 innovator programs, coaches and peers.

Participants implemented or adapted one or both of 2 previously established remote consult services in their jurisdictions: the Champlain BASE eConsult service and the RACE service. ${ }^{10}$

\section{Services}

\section{Champlain BASE eConsult service}

The Champlain BASE eConsult service is a secure online platform that allows primary care providers to submit nonurgent cases to a regional or provincial managed service, defined as a group of specialists responding to eConsults for a given specialty or subspecialty. BASE is a model of care, not a specific technology, and as such can be adopted on any digital platform capable of facilitating secure communication between providers.
In the BASE model of care, primary care providers log into the platform, enter a clinical question regarding the patient's care and select the most relevant specialty group from the list of available specialties. A case assigner directs the eConsult to an appropriate specialist based on availability. The specialist responds to the primary care provider's question within 1 week by providing advice on how to manage the patient's care, recommending that the patient receive a face-to-face referral (not necessarily with them) or requesting additional information. Primary care providers can then respond with additional questions or close the case.

Launched as a small proof-of-concept project and soon expanded to a full pilot in Eastern Ontario, the service has, as of March 2021, completed more than 80000 eConsults, enrolled more than 1700 primary care providers and provides access to 135 specialty groups. Specialists respond to cases in a median of 1.9 days. ${ }^{11}$ Previous efforts to expand the service have shown its generalizability to new health jurisdictions. ${ }^{12}$ Given that the purpose of the Connected Medicine collaborative was to expand innovations in regions where they were not already present, the Ontario BASE service was not part of the collaborative, and its data, reported elsewhere, ${ }^{11}$ were not included in this study.

\section{RACE service}

The RACE service is a shared care model that allows primary care providers to contact specialists by telephone to ask clinical questions concerning a specific patient's care. Unlike the BASE service, which allows for asynchronous messages to be sent and answered at a later date, RACE facilitates synchronous (i.e., "real-time") bidirectional conversations between providers and is designed for use when more urgent advice is needed. The model is set up to provide advice and not a full consultation, although some specialties can facilitate a full consult if needed or advise to refer to a local specialist.

Launched at Providence Health Care in Vancouver in 2010, the service operates in the Vancouver Coastal Health region, offers a subset of 23 specialties to primary care providers province-wide, has a roster of about 300 specialists and as of January 2021 had logged more than 75000 calls. Primary care providers can call the RACE line between 8 am and 5 pm (Pacific time) Monday to Friday and can choose to be connected with a specialist from 1 of 50 available specialty groups. The specialist will call the primary care provider back within 2 hours to provide advice and discuss the patient's care.

\section{Outcomes}

To measure the impact of the programs implemented through the collaborative, we assessed them on the following metrics: usage (i.e., number of cases completed, average specialist response time), number of specialties available, impact on primary care provider's decision to refer and impact on emergency department visits. Together, these metrics illustrate the extent to which the service was adopted by users and what effect it had on patient care. 


\section{Data collection}

Each participating team contributed data collected by the service through 2 sources, where available: utilization data and surveys.

\section{Utilization data}

As part of their respective operating procedures, the BASE and RACE services collect data automatically for each case (defined for BASE as a primary care provider's question and specialist's response, plus any further exchanges until the primary care provider chooses to close the case, and for RACE as a primary care provider's call and subsequent discussion with the specialist). A summary of these data allows each service to tabulate the number of cases per month, the number of primary care providers submitting cases, the number of specialists responding to cases and the number of specialties available. Additionally, programs using the BASE model input a time stamp on each submitted question or response, allowing for the calculation of average specialist response time.

\section{Surveys}

As part of the BASE model, primary care providers complete a brief survey at the conclusion of each case assessing the case's impact on their course of action and decision to refer. Our study used data only from the second question of the BASE survey, which asked them to indicate whether they had originally intended to refer the patient and whether the eConsult led them to change their original decision. A copy of the survey used by BASE services is available in Appendix 1 (available at www.cmajopen.ca/content /9/4/E1187/suppl/DC1).

Unlike the BASE model, which includes a close-out survey as part of its design, the RACE model of care does not include a built-in mechanism to collect feedback from users, and the decision of whether or not to survey users was up to the individual programs. As such, some of the programs that adopted the RACE model could not supply this information.

Two programs using RACE did conduct surveys of users. One of these programs (Fraser RACE) incorporated a survey into the service's app, which primary care providers were prompted to complete upon the conclusion of each case. The survey assessed whether the case resulted in the patient avoiding a referral where one would have otherwise been ordered and also whether the case resulted in the patient not being sent to the emergency department where an emergency department visit would otherwise have been contemplated (Appendix 2, available at www.cmajopen.ca/content/9/4/ E1187/suppl/DC1). A second program using RACE (Alberta Health Services [AHS] Calgary Zone Specialist LINK) presented specialists with a brief survey to complete after each call, for submission by email or fax, in which they summarized the purpose and outcome of the call, and indicated whether an emergency department visit was avoided (Appendix 3, available at www.cmajopen.ca/content/9/4/E1187/supp1/DC1). Both surveys of the RACE service were voluntary.

\section{Statistical analysis}

We used descriptive statistics (calculated with Microsoft Excel) to assess the impact of implemented services in each jurisdiction.

\section{Ethics approval}

The Ottawa Health Science Network and Bruyère research ethics boards provided ethics approval for this project (protocol no. 2009848-01H).

\section{Results}

Ten provincial teams participated in the Connected Medicine collaborative. Of these, 5 implemented services using or adapted from the BASE model and 4 implemented services using or adapted from the RACE model, while AHS implemented services using both the BASE (AHS Calgary eReferral) and RACE (AHS Calgary Zone Specialist LINK) models. The final data set therefore included 11 programs from 10 teams. Details of the participating programs are available in Table 1.

\section{Date joined}

Participating teams joined the collaborative at different stages of implementation, with some having already adopted services and focusing on expansion, and others starting without any prior implementation work. Seven teams focused on expanding programs already established before the start of the collaborative, whereas 3 teams launched new programs during the collaborative period. ${ }^{13}$ As a result, the date ranges for usage data varied considerably among programs, with some teams providing data from as early as May 2017 (a month before the official start of the collaborative) and others providing shorter data sets. The most extensive data set ranged from May 2017 to March 2019 (eConsult Quebec), and the shortest spanned 6 months, from May to October 2018 (eConsult NB).

\section{Usage}

The participating programs reported a combined total of 13459 completed cases. Case volume differed considerably among programs, from 97 cases (eConsult NB) to 6792 cases (AHS Calgary Zone Specialist LINK) (Figure 1). The average number of cases per month ranged from 14.7 (BASE eConsult $\mathrm{MB})$ to 424.5 (AHS Calgary Zone Specialist LINK). Among the 5 programs that collected specialist response times, a range of $80 \%$ (AHS Calgary eReferral; $n=294 / 368$ ) to $93 \%$ (BASE eConsult MB; $n=164 / 176$ ) of cases received responses within 7 days (Figure 2).

\section{Specialties available}

Programs offered access to multiple specialty groups, with menus ranging from 5 specialties (eConsult NB) to 37 specialties (NL BASE). For most programs, the number of available specialties did not remain static throughout the duration of the project but increased over time as new specialists were onboarded (Figure 3). BASE eConsult MB showed the largest 


\begin{tabular}{|c|c|c|c|c|c|c|}
\hline Program name & $\begin{array}{l}\text { Service } \\
\text { type }\end{array}$ & $\begin{array}{c}\text { Date of } \\
\text { program } \\
\text { launch }\end{array}$ & Date range for data & $\begin{array}{c}\text { No. of } \\
\text { cases } \\
\text { completed }\end{array}$ & $\begin{array}{c}\text { Mean } \\
\text { no. of } \\
\text { cases/mo }\end{array}$ & $\begin{array}{c}\text { No. of } \\
\text { specialties } \\
\text { available* }^{*}\end{array}$ \\
\hline \multicolumn{7}{|l|}{ Alberta } \\
\hline AHS Calgary eReferral & BASE & July 2014 & $\begin{array}{l}\text { August 2017- } \\
\text { February } 2019\end{array}$ & 398 & 20.9 & 15 \\
\hline AHS Calgary Zone Specialist LINK & RACE & July 2014 & $\begin{array}{l}\text { August 2017- } \\
\text { November } 2018\end{array}$ & 6792 & 424.5 & 15 \\
\hline \multicolumn{7}{|l|}{ British Columbia } \\
\hline Fraser RACE Team & RACE & $\begin{array}{l}\text { January } \\
2014\end{array}$ & $\begin{array}{l}\text { December 2017- } \\
\text { November } 2018\end{array}$ & 401 & 33.4 & 10 \\
\hline Interior EASE & RACE & $\begin{array}{l}\text { January } \\
2015\end{array}$ & $\begin{array}{l}\text { December 2017- } \\
\text { November } 2018\end{array}$ & 612 & 51 & 7 \\
\hline RACE North & RACE & June 2012 & $\begin{array}{l}\text { October 2017- } \\
\text { November } 2018\end{array}$ & 567 & 40.5 & 13 \\
\hline Providence eCASE & BASE & April 2017 & $\begin{array}{c}\text { May 2017- } \\
\text { December } 2018\end{array}$ & 934 & 46.7 & - \\
\hline \multicolumn{7}{|l|}{ Manitoba } \\
\hline BASE eConsult MB & BASE & $\begin{array}{c}\text { December } \\
2017\end{array}$ & $\begin{array}{l}\text { December 2017- } \\
\text { November } 2018\end{array}$ & 176 & 14.7 & 26 \\
\hline \multicolumn{7}{|l|}{ New Brunswick } \\
\hline eConsult NB & BASE & May 2018 & $\begin{array}{c}\text { May 2018- } \\
\text { October } 2018\end{array}$ & 97 & 16.1 & 5 \\
\hline \multicolumn{7}{|l|}{ Newfoundland and Labrador } \\
\hline NL BASE & BASE & $\begin{array}{l}\text { November } \\
2016\end{array}$ & $\begin{array}{l}\text { September 2017- } \\
\text { November } 2018\end{array}$ & 1716 & 114.4 & 37 \\
\hline \multicolumn{7}{|l|}{ Quebec } \\
\hline eConsult Quebec & BASE & May 2017 & $\begin{array}{l}\text { May 2017- } \\
\text { March 2019 }\end{array}$ & 1389 & 60.4 & 22 \\
\hline \multicolumn{7}{|l|}{ Saskatchewan } \\
\hline Saskatchewan LINK & RACE & March 2016 & $\begin{array}{c}\text { May 2017- } \\
\text { December } 2018\end{array}$ & 377 & 18.9 & 7 \\
\hline
\end{tabular}

increase in available specialties, growing from 5 in December 2017 to 26 in November 2018.

\section{Impact on decisions to refer}

Five programs using the BASE service and 1 program using the RACE service (Fraser RACE Team) provided survey responses exploring the proportion of cases concluded without resulting in a face-to-face specialist referral. In 3 services (AHS Calgary eReferral, BASE eConsult MB, eConsult Quebec), the close-out survey was mandatory, resulting in $100 \%$ response rates. Response rates for the remaining programs were $43 \%$ (Fraser RACE Team; $n=$ 171/401), 46\% (eConsult NB; $n=45 / 97$ ) and 62\% (NL BASE; $n=1066 / 1716)$. The proportion of cases resolved without the patient needing a face-to-face specialist visit ranged from 48\% (eConsult Quebec; $n=667 / 1389$ ) to $76 \%$ (AHS Calgary eReferral; $n=302 / 398$ ) (Figure 4).

\section{Impact on emergency department visits}

Two telephone consult programs provided data on their impact on emergency department visits: the Fraser RACE Team ( $n=171 / 401$, response rate $43 \%)$ and the AHS Calgary Zone Specialist LINK $(n=492 / 6792$, response rate $7 \%)$. Primary care providers using the Fraser RACE Team program reported that $74 \%$ of cases $(n=127 / 171)$ resulted in patients not being sent to the emergency department, where an emergency department visit would have been contemplated without a remote consult. For the AHS Calgary Zone Specialist LINK program, the rate of avoidance of potential emergency department visits was 28\% $(n=138 / 492)$.

\section{Interpretation}

The programs implemented through the Connected Medicine collaborative had a positive effect on patient care, as seen 


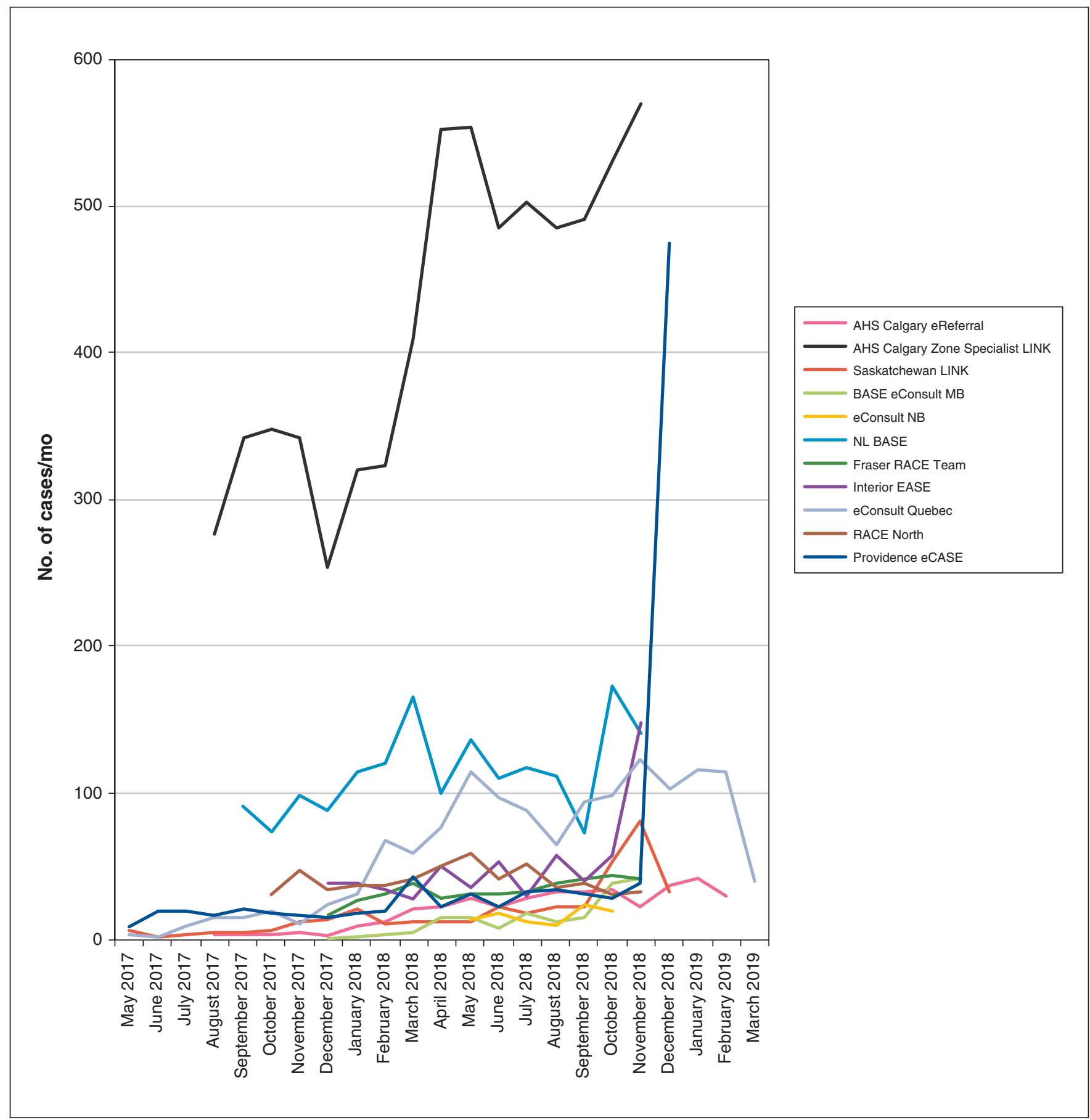

Figure 1: Monthly case volumes for participating programs. See Table 1 for details about the period of data collection for each program. The study analyzed data from June 2017 to December 2018.

through impacts on primary care providers' decisions to refer and on emergency department visits. All teams that participated in the collaborative were able to implement their chosen innovations. The scope of implementation varied, but all teams sustained their innovations for the duration of the collaborative and beyond, showing growth in utilization. Most programs added new specialties during the study period, which suggests that recruitment efforts extended beyond the initial launch. Responses from primary care provider surveys, where available, described encouraging impact on avoidance of unnecessary specialist and emergency department visits, as well as quick response times from specialists.

Several studies have explored implementation barriers affecting virtual care innovations such as BASE and RACE. Major barriers identified by multiple studies include increases in physician workload, ${ }^{14-16}$ a lack of resources or funding ${ }^{15-17}$ and resistance to change. ${ }^{14,16}$ The collaborative avoided or mitigated these issues by connecting motivated 


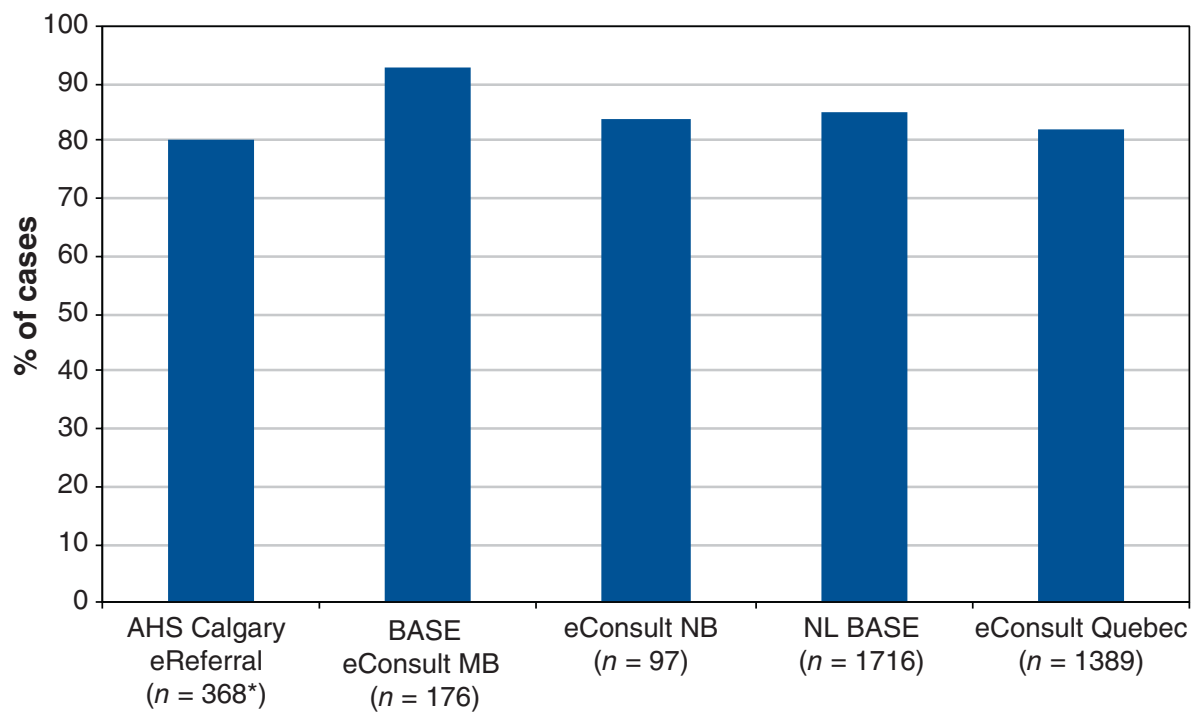

Figure 2: Percentage of cases completed within 7 days of submission, by program (for the 5 programs collecting these data). *Excludes data (for 30 cases) from February 2019.

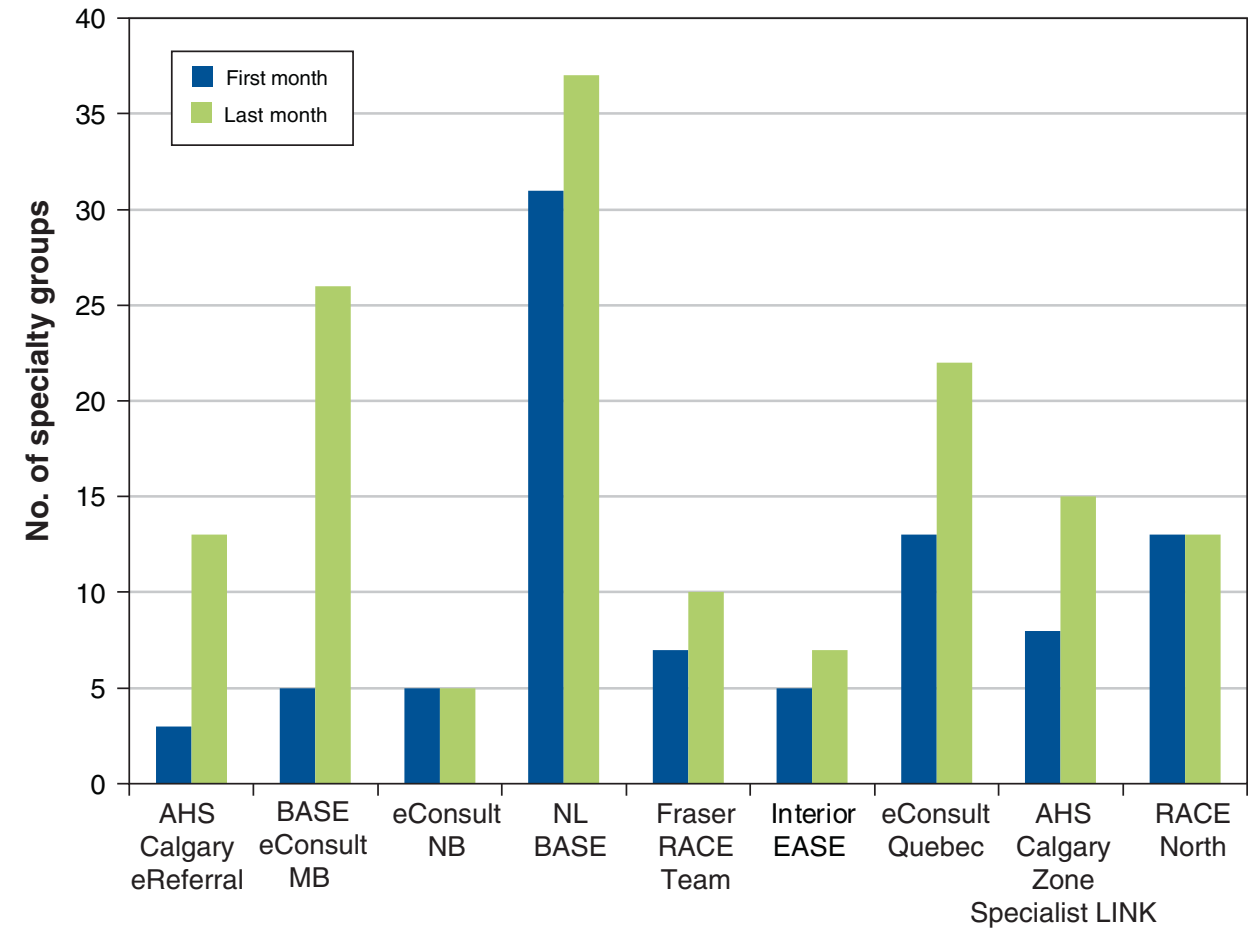

Figure 3: Number of specialty groups available from each program (for the 9 programs collecting these data) at first and last month of available data.

teams with knowledgeable innovators and proven innovations. One of the cornerstones of the collaborative's approach to implementation was its focus on quality improvement, change management and facilitation of coaching directly with innovators. The collaborative put groups interested in implementing virtual care solutions in direct contact with representatives from the original BASE and RACE teams, whose experience allowed them to provide solutions for challenges faced during the initial implementation and to offer a sense of the initiative's 


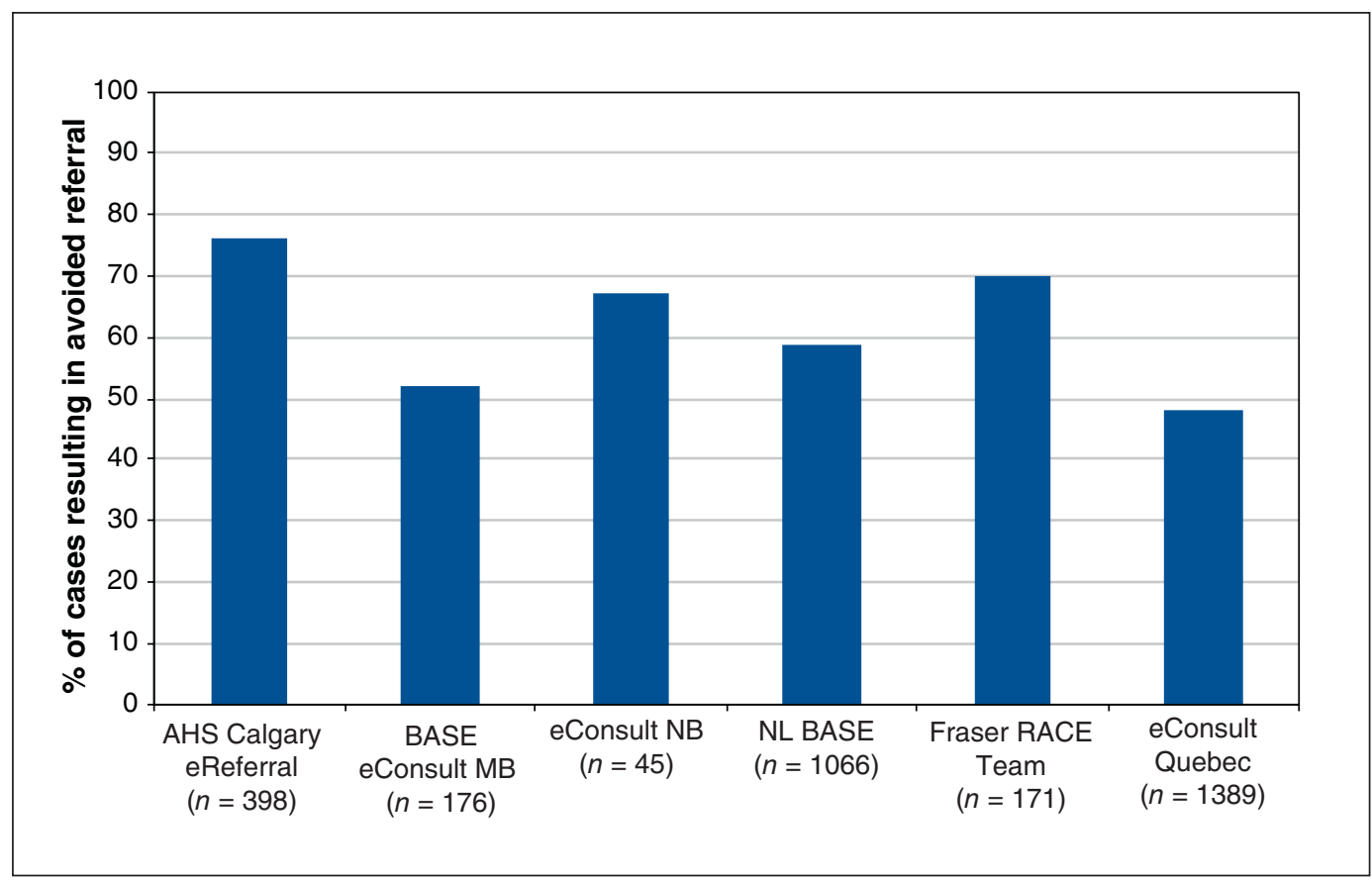

Figure 4: Percentage of cases resolved without the patient needing a face-to-face specialist visit, by program (for the 6 programs collecting these data).

trajectory. Meanwhile, the teams seeking to adopt the innovations provided an understanding of local needs and connections with regional providers that an organization imposing a top-down implementation could not easily provide.

The BASE and RACE services have continued to expand in the wake of the collaborative. Programs using the BASE model of care are now underway or operational in 9 provinces and territories across Canada, accounting for a combined total of more than 80000 completed cases, while RACE has completed more than 75000 calls. ${ }^{18} \mathrm{Mul}-$ tiple analyses of BASE data have shown consistently that in $40 \%$ of cases, a face-to-face referral was originally considered by the primary care provider but was avoided because of the advice contained in the eConsult. ${ }^{11}$ A 2016 study of the RACE service found that $60 \%$ of cases resulted in the patient avoiding a face-to-face specialist visit. ${ }^{19}$ These figures have been largely replicated by the collaborative teams. ${ }^{13}$ Using these numbers, we estimate that 51000 patients had improved access to specialist care as a direct consequence of these 2 services. Given the cost of specialist appointments to the health care system, combined with the consequences of excessive wait times on patient outcomes and anxiety and the reduction in costs associated with referrals (travel costs, missed work, etc.), the benefit of these services has been considerable, particularly given that economic evaluations of the Ontario BASE service have shown substantial cost savings relative to the traditional referral-consultation model. ${ }^{20}$ Additional expansion, supported by the collaborative and other such initiatives, would further increase their impact.

\section{Limitations}

Our study had several limitations. Although 10 teams participated in the study, they began implementation at different times, and the method, frequency and duration of their data reporting varied, which made comparisons across programs more difficult and limited our ability to quantify the collaborative's precise impact on individual programs. The collaborative also supported the implementation of 2 distinct services - BASE and RACE - that, despite sharing a common goal of improving access to specialist advice, pursued different models of care delivery; these differences also made direct comparison challenging.

Not all of the teams conducted surveys of primary care providers, and those that did used various methods that resulted in a range of response rates. The response rate for AHS Calgary Zone Specialist LINK was particularly low, at only $7 \%$, which may have caused that sample to be less representative. This also raises a challenge for comparisons across programs, particularly between those that instituted mandatory surveys and those in which surveys were voluntary.

The metrics used to assess impact were selected on the basis of available data, which, while useful, relied exclusively on reporting by primary care providers. There was no way to follow the individual cases of patients whose primary care providers cited "avoided referral" to confirm that a referral was not made for a related reason sometime in the future. Likewise, the reporting of emergency department avoidance speaks only to decisions by individual primary care providers and cannot be used to measure any change in overall rates of referral to the emergency department. 


\section{Conclusion}

The 2 innovative virtual care solutions implemented through the Connected Medicine collaborative received widespread usage and affected primary care providers' decisions to refer patients to specialists. The success of these services in multiple settings shows that they represent an effective means of sustaining implementation of a virtual care innovation beyond the pilot phase and supporting its continued spread and scale.

\section{References}

1. How Canada compares: results from the Commonwealth Fund's 2016 international bealth policy survey of adults in 11 countries. Ottawa: Canadian Institute for Health Information; 2017. Available: www.cihi.ca/sites/default/files/ document/text-alternative-version-2016-cmwf-en-web.pdf (accessed 2017 July 14).

2. Health care in Canada, 2012: a focus on wait times. Ottawa: Canadian Institute for Health Information. Available: https://publications.gc.ca/collections/ collection_2013/icis-cihi/H115-15-2012-eng.pdf (accessed 2021 Nov. 30).

3. Jaakkimainen L, Glazier R, Barnsley J, et al. Waiting to see the specialist: patient and provider characteristics of wait times from primary to specialty care. BMC Fam Pract 2014;15:16.

4. Thind A, Stewart M, Manuel D, et al. What are wait times to see a specialist? An analysis of 26,942 referrals in southwestern Ontario. Healthc Policy 2012;8:80-91.

5. Thanh NX, Wanke M, McGeachy L. Wait time from primary to specialty care: a trend analysis from Edmonton, Canada. Healthc Policy 2013;8:35-44.

6. Neimanis I, Gaebel K, Dickson R, et al. Referral processes and wait times in primary care. Can Fam Physician 2017;63:619-24.

7. Bégin M, Eggertson L, Macdonald N. A country of perpetual pilot projects. CMA7 2009; 180:1185.

8. Unleashing innovation: excellent healthcare for Canada: report of the Advisory Panel on Healthcare Innovation. Ottawa: Health Canada; 2015.

9. Greenhalgh T, Papoutsi C. Spreading and scaling up innovation and improvement. BMF 2019;365:12068.

10. Connected medicine: enhancing primary care access to specialist consult. Ottawa: Canadian Foundation for Healthcare Improvement. Available: www.cfhi-fcass.ca/What WeDo/connected-medicine (accessed 2018 Oct. 12).

11. Liddy C, Moroz I, Afkham A, et al. Sustainability of a primary care driven eConsult service. Ann Fam Med 2018;16:120-6.

12. Liddy C, Bello A, Cook J, et al. Supporting the spread and scale-up of electronic consultation across Canada: cross-sectional analysis. BMF Open 2019;9:e028888.

13. Connected medicine: enhancing primary care access to specialist consult: an 18-month quality improvement collaborative - backgrounder. Ottawa: Canadian Foundation for Healthcare Improvement. Available: www.cfhi-fcass.ca/docs/default-source/ news-and-stories/connected-medicine-backgrounder-e.pdf?sfvrsn=a4ecf82d_2 (accessed 2020 Feb. 13).

14. Tuot DS, Leeds K, Murphy EJ, et al. Facilitators and barriers to implementing electronic referral and/or consultation systems: a qualitative study of 16 health organizations. BMC Health Serv Res 2015;15:568.

15. Osman MA, Schick-Makaroff K, Thompson S, et al. Barriers and facilitators for implementation of electronic consultations (eConsult) to enhance access to specialist care: a scoping review. BM7 Glob Health 2019;4:e001629.

16. Joschko J, Keely E, Grant R, et al. Electronic consultation services worldwide: environmental scan. 7 Med Internet Res 2018;20:e11112.

17. Brown V, Fuller J, Ford D, et al. The enablers and barriers for the uptake, utilization, sustainability and spread of primary health care collaboratives in Australia. Canberra (Australia): University of Queensland, APHCRI Centre of Research Excellence in Primary Health Care Microsystems. Available: https://www.researchgate.net/publication/284511076_The_enablers_and_ barriers_for_the_uptake_use_and_spread_of_primary_health_care_ Collaboratives_in_Australia (accessed 2020 Jan. 10).

18. What is RACE? Vancouver: RACE Rapid Access to Consultative Expertise. Available: www.raceconnect.ca/about-race/what-is-race/ (accessed 2020 Jan. 3).
19. Wilson M, Mazowita G, Ignaszewski A, et al. Family physician access to specialist advice by telephone: reduction in unnecessary specialist consultations and emergency department visits. Can Fam Physician 2016;62:e668-76.

20. Liddy C, Keely E. Using the quadruple aim framework to measure impact of health technology implementation: a case study of eConsult. 7 Am Board Fam Med 2018;31:445-55.

Affiliations: C.T. Lamont Primary Health Care Research Centre, Department of Family Medicine (Liddy, Crowe), Department of Medicine (Keely), University of Ottawa; eConsult Centre of Excellence (Liddy, Keely), The Ottawa Hospital; Bruyère Research Institute (Crowe); Canadian Foundation for Healthcare Improvement (Drimer, Kirvan), Ottawa, Ont.; New Brunswick Medical Society (Boulay), Fredericton, NB; Department of Family Medicine (Dumas-Pilon), McGill University, Montréal, Que.; Department of Family Medicine (Farrell), Memorial University of Newfoundland, St. John's, NL; Nine Circles Community Health Centre (Ireland) and Department of Family Medicine (Singer), University of Manitoba, Winnipeg, Man.; Université du Québec en Outaouais (Nabelsi), Gatineau, Que.; Providence Health Care (Wilson), Vancouver, BC

Contributors: Clare Liddy and Erin Keely conceived of and designed the study, and contributed to the data analysis and drafting of the publication. Emma Boulay led the collection, analysis and interpretation of the data for one of the teams involved in the Connected Medicine collaborative and contributed to the review and editing of the article. Lois Crowe also contributed to the design of the study, data collection and revision of the manuscript. Maxine DumasPilon contributed to the data collection for one of the teams involved in the collaborative, and reviewed and edited the manuscript. Neil Drimer and Christine Kirvan contributed to the design of the study, review, editing and data analysis of the publication. Gerard Farrell was involved in designing the study, collecting and analyzing data, and contributed to the review and editing of the publication. Laurie Ireland led data collection and analysis for one of the teams involved in the collaborative, and has edited and reviewed the publication. Veronique Nabelsi led the data collection for one of the teams involved in the collaborative and contributed to the review and editing of the publication. Alexander Singer led the data collection for one of the teams involved in the collaborative and contributed to the review and editing of the publication. Margot Wilson participated in developing the design for the collaborative and in the writing, editing and reviewing of the manuscript. All of the authors approved the final version for publication and agreed to be accountable for the work.

Funding: This research was supported by the Canadian Foundation for Healthcare Improvement (now part of Healthcare Excellence Canada) and the Canadian Institutes of Health Research.

Content licence: This is an Open Access article distributed in accordance with the terms of the Creative Commons Attribution (CC BY-NC-ND 4.0) licence, which permits use, distribution and reproduction in any medium, provided that the original publication is properly cited, the use is noncommercial (i.e., research or educational use), and no modifications or adaptations are made. See: https://creativecommons.org/licenses/ by-nc-nd/4.0/

Data sharing: Data from the study are available from the corresponding author upon reasonable request.

Acknowledgements: The authors thank all of the teams that participated in the Canadian Foundation for Healthcare Improvement Connected Medicine collaborative, as well as the primary care providers, specialists and patient-partners who were involved. They also thank Justin Joschko and Jessi Hammond for their help in preparing this manuscript.

Supplemental information: For reviewer comments and the original submission of this manuscript, please see www.cmajopen.ca/content/9/4/ E1187/suppl/DC1. 